\title{
The Effect of processing on the PVC/Clay Nanocomposites Structure
}

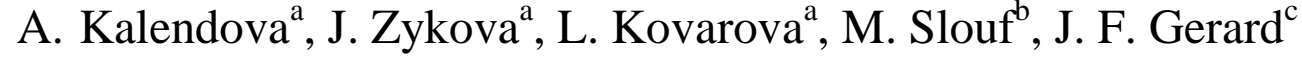 \\ ${ }^{a}$ Department of Polymer Engineering, Faculty of Technology, Tomas Bata University in Zlín, \\ Nám.TGM 275, 76272 Zlín, Czech Republic, kalendova@email.cz \\ ${ }^{b}$ Institute of Macromolecular Chemistry AS CR, Prague, Czech Republic \\ ${ }^{c}$ Laboratoire des Matériaux Macromoléculaires IMP INSA de Lyon, Bât Jules Verne, 20 Avenue A. Einstein, \\ 69621 Villeurbanne Cedex - France
}

\begin{abstract}
Reported nanocomposites of poly(vinyl chloride) have been prepared using bentonite-based clay, Namontmorillonite (nature clay) and organophilic clay 30B. Polymer nanocomposites of differing compositions were produced using Buss KO-kneader via melt intercalation method. The effect of different type of plasticizer (both low molecular and high molecular) and compounding conditions on the structure of PVC/clay nanocomposites was investigated. Different compounding conditions were tested to study their influence on nanoparticles dispersion, orientation and exfoliation in PVC/clay nanocomposites. The structure of PVC/MMT nanocomposites was observed using X-ray diffraction, transmission electron microscopy (TEM) and AFM (Atomic Force Microscopy). It was found that the Na-montmorillonite offer low exfoliation level, while 30B modified by plasticizer exhibits fine dispersion of partial to nearly full exfoliated MMT. Moreover the processing conditions play also important role in nanocomposite production.
\end{abstract}

Keywords: Polyvinylchloride, nanocomposite, morphology, microscopy.

PACS: 81.07.Pr Organic-inorganic hybrid nanostructures

\section{INTRODUCTION}

Polymer-layered silicate nanocomposites (PLS) have experienced an important development over the past 20 years. PLS has been the focus of academic and industrial attention because the final composites often exhibit a desired enhancement of mechanical, barrier, thermal or other properties relative to the original polymer matrix, even at very low clay contents. ${ }^{[1-4]}$

The most commonly used layered silicate in PLS is montmorillonite (MMT), a layered aluminosilicate smectite clay. A sheet structure consists of octahedral alumina sandwiched between two silica tetrahedral layers. Negatively charged, massive silicate sheets are separated by interlayer regions of 5-10 $\AA$, which contain charge-compensating mobile cations.. ${ }^{[5]}$ Moreover, montmorillonite has a low cation-exchange capacity (CEC) and, therefore, does not have a large number of ionic interactions holding the clay plates together. ${ }^{[6]}$

Polyvinylchloride (PVC) is a polymer, which has a lot of characteristics suitable for industrial applications such as good mechanical properties, fire retardancy, good processability and, in addition, it offers the advantage of low cost. ${ }^{[7]}$ Despite the fact that PVC is one of the major thermoplastic polymers, PVC/clay nanocomposites are still in the introductory phase. This work is based on the study of the influence of different processing conditions, and various plasticizers on the morphology of PVC/clay nanocomposites.

\section{EXPETIMENTAL}

\section{Materials and PVC/Clay Processing}

The suspension type of PVC Neralit $652(\mathrm{~K}=65)$ from Spolana Neratovice, Czech Republic was used as polymer matrix. The samples were stabilized with $3 \%$ Lankromark LZB 968. As a filler was employed bentonitebased clay, Na-montmorillonite and organophilic montmorillonite 30B from Southern Clay Products, USA. Na-

CP1255, $\mathrm{V}^{\text {th }}$ Intemational Conference on Tim es of Polym ers (TO P) and Composites, edited by A .D 'A m ore, D .A ciemo, and L . G rassia

(c) 2010 A m erican Institute of Physics 978-0-7354-0804-3/10/\$30.00 
montmorillonite is a sodium type with $d$ spacing $1,2 \mathrm{~nm}$. Montmorillonite 30B is organophilic clay with $d$ spacing $1.8 \mathrm{~nm}$. Dioctylphthalate (DOP), dioctyladipate (DOA) and polyester Lankroflex PLA (PLA) were used as PVC plasticizer and montmorillonite modifiers.

The PLS were prepared in a Buss KO-kneader MKS $30(\mathrm{~L} / \mathrm{D}=18, \mathrm{D}=30 \mathrm{~mm})$. The screw speed was at 80, 50, $35,25 \mathrm{rpm}$. The operating temperature was at range $130-160{ }^{\circ} \mathrm{C}$. Selected blends were compounded two or three times. Table 1 shows overview of tested samples and conditions.

TABLE 1. PVC/Clay Composition and Processing Conditions

\begin{tabular}{|c|c|c|c|c|c|c|c|}
\hline Composition & & $\begin{array}{l}\mathbf{v}_{\text {screw }} \\
(\mathbf{r p m})\end{array}$ & $\begin{array}{c}\mathbf{t} \\
\text { (times) }\end{array}$ & Composition & $\begin{array}{c}\text { Filler } \\
(\%)\end{array}$ & $\begin{array}{l}\mathbf{v}_{\text {screw }} \\
(\mathbf{r p m})\end{array}$ & $\begin{array}{c}\mathbf{t} \\
\text { (times) }\end{array}$ \\
\hline PVC/DOP 50 & 0 & 50 & $\mathrm{t}$ & & & & \\
\hline PVC/DOA 50 & 0 & 50 & $\mathrm{t}$ & & & & \\
\hline PVC/PLA 50 & 0 & 50 & $\mathrm{t}$ & & & & \\
\hline $\mathrm{PVC} / 30 \mathrm{~B} / \mathrm{DOP} 80$ & 5 & 80 & $\mathrm{t}$ & $\mathrm{PVC} / \mathrm{Na} / \mathrm{DOP} 80$ & 5 & 80 & $\mathrm{t}$ \\
\hline PVC/30B/DOP 80 & 5 & 80 & $2 \mathrm{t}$ & $\mathrm{PVC} / \mathrm{Na} / \mathrm{DOP} 80$ & 5 & 80 & $2 \mathrm{t}$ \\
\hline PVC/30B/DOP 50 & 5 & 50 & $\mathrm{t}$ & $\mathrm{PVC} / \mathrm{Na} / \mathrm{DOP} 50$ & 5 & 50 & $\mathrm{t}$ \\
\hline PVC/30B/DOP 50 & 5 & 50 & $2 \mathrm{t}$ & $\mathrm{PVC} / \mathrm{Na} / \mathrm{DOP} 50$ & 5 & 50 & $2 \mathrm{t}$ \\
\hline PVC/30B/DOP 50 & 5 & 50 & $3 \mathrm{t}$ & $\mathrm{PVC} / \mathrm{Na} / \mathrm{DOP} 50$ & 5 & 50 & $3 \mathrm{t}$ \\
\hline $\mathrm{PVC} / 30 \mathrm{~B} / \mathrm{DOA} 50$ & 5 & 50 & $\mathrm{t}$ & $\mathrm{PVC} / \mathrm{Na} / \mathrm{DOA} 50$ & 5 & 50 & $\mathrm{t}$ \\
\hline PVC/30B/PLA 50 & 5 & 50 & $\mathrm{t}$ & PVC/Na/PLA 50 & 5 & 50 & $\mathrm{t}$ \\
\hline $\mathrm{PVC} / 30 \mathrm{~B} / \mathrm{DOP} 35$ & 5 & 35 & $\mathrm{t}$ & $\mathrm{PVC} / \mathrm{Na} / \mathrm{DOP} 35$ & 5 & 35 & $\mathrm{t}$ \\
\hline PVC/30B/DOP 35 & 5 & 35 & $2 \mathrm{t}$ & PVC/Na/DOP 35 & 5 & 35 & $2 \mathrm{t}$ \\
\hline PVC/30B/DOP 25 & 5 & 25 & $\mathrm{t}$ & $\mathrm{PVC} / \mathrm{Na} / \mathrm{DOP} 25$ & 5 & 25 & $\mathrm{t}$ \\
\hline PVC/30B/DOP 25 & 5 & 25 & $2 \mathrm{t}$ & $\mathrm{PVC} / \mathrm{Na} / \mathrm{DOP} 25$ & 5 & 25 & $2 \mathrm{t}$ \\
\hline
\end{tabular}

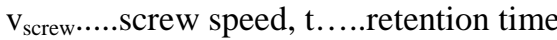

\section{Structural Study}

The structure of obtained materials was observed by XRD and microscopic analysis. X-ray diffraction data were obtained at room temperature by an URD-6 Diffractometer, the X-ray beam was nickel-filtered CuK $\alpha_{1}(\lambda=1,54 \AA)$ radiation.

The dispersion and delamination of the clays in PVC matrix were observed through microscopic technique. For the transmission electron microscopy (TEM, Phillips PM 120) the specimens were cut using an ultramicrotome equipped with a diamond knife. For the atomic force microscopy (AFM, Explorer ${ }^{\mathrm{TM}}$ ) were used the same samples as for TEM. It was used non-contact AFM method and for profile determination was applied software SPM Lab 5.01.

\section{RESULT AND DISCUSSION}

\section{X-Ray Diffraction and Microscopy}

$\mathrm{X}$-ray reflectivity is one of the most powerful techniques to study the structural aspects of intercalates and nanostructures. Figer 1 represent the XRD patterns PVC/30B nanocomposites produced with Buss KO-kneader.
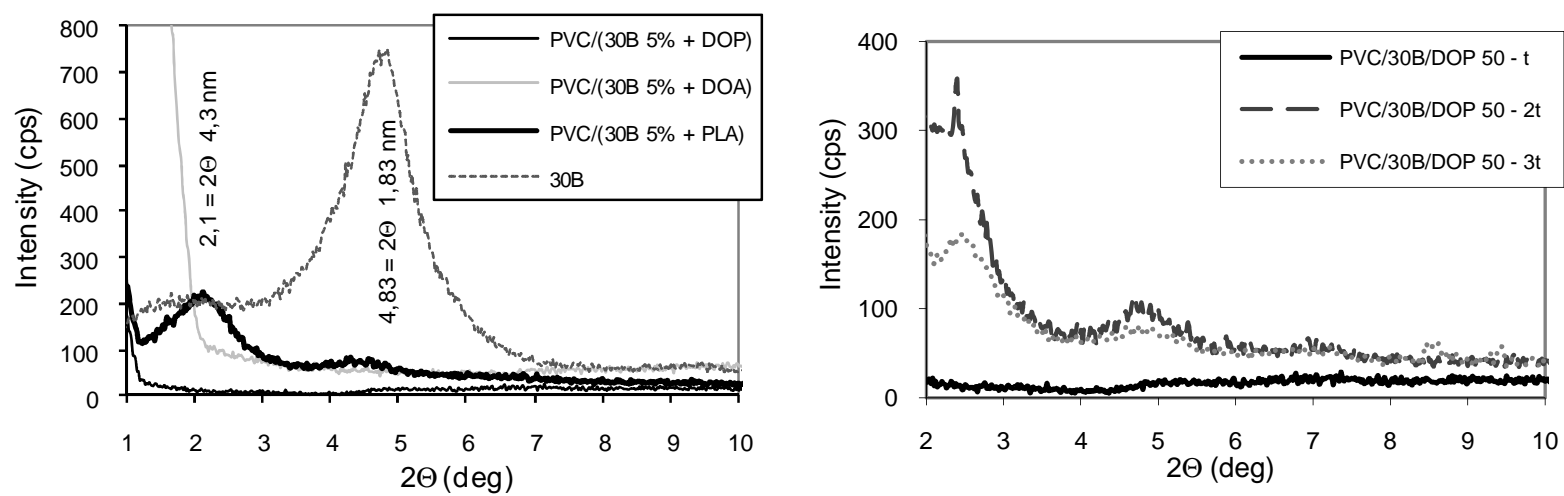

FIGURE 1. XRD Patterns a) PVC/30B $50-\mathrm{t}$, b) PVC/30B/DOP $50-\mathrm{t}, 2 \mathrm{t}, 3 \mathrm{t}$ 
The XRD measurement of PVC nanocomposites (Figure 1a) confirms good exfoliation by samples with montmorillonite 30B/DOP, 30B/DOA (low molecular plasticizers). It can indicate good level of filler exfoliation to polymer matrix, and this result was confirmed by TEM (Figure 2). For the PVC/30B/PLA, changes in the structure of clay 30B in presence of plasticizer PLA (high molecular plasticizer) were observed, the $d$ spacing increased from 1.83 to $4.3 \mathrm{~nm}$. On the other hand, the compositions base on Na-montmorillonite does not show changes in XRD pattern and low level of exfoliation was also confirmed by TEM.

In Figure $1 \mathrm{~b}$ are presented XRD patterns PVC/30B/DOP compositions prepared by different retention time t. It was noticed, that the composition shows some ordered structures, which could be probably connected with stacks of several layers which were not fully exfoliated. In Figure 3, it can be seen that the silicate layers are dispersed evenly in the polymer matrix. It was observed that the longer time of mixing in the Buss KO-kneader caused regular dispersion and orientation of the nanoparticles in the PVC matrix. On the other hand too long retention time leads to the destruction of exfoliated layers. For various retention time $\mathrm{t}$ for PVC/Na composites, it was not noticed dramatic changes in the structure of PVC/Na/DOP. The $d$ spacing moved from 1.2 to $1.3 \mathrm{~nm}$.

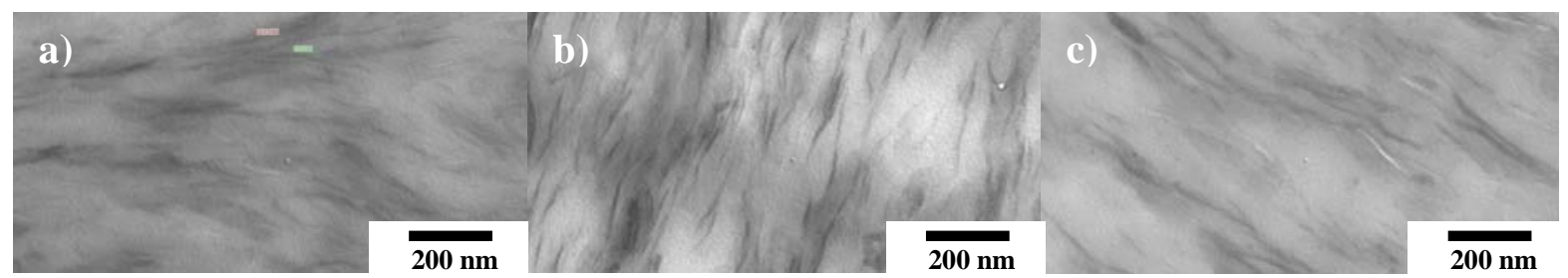

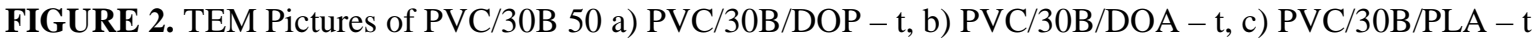

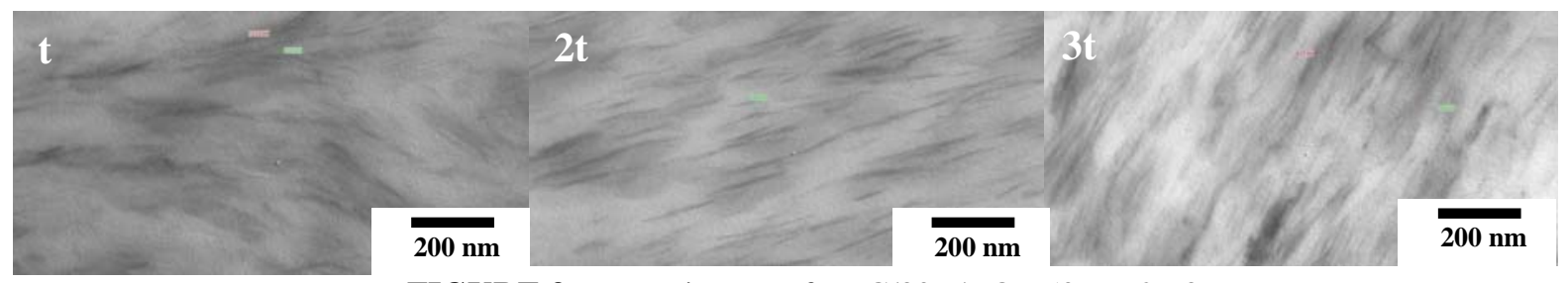

FIGURE 3. TEM Pictures of PVC/30B/DOP $50-t, 2 t, 3 t$

\section{CONCLUSION}

PVC/clay nanocomposites were obtained via melt compounding of PVC with clay in the presence of low and high molecular plasticizers. The type of plasticizer play important role in the process of intercalation or cointercalation of montmorillonite and could be helpful during the nanocomposite processing. Better results give low molecular plasticizers.

Next the different processing conditions were tested. It could be concluded, that the lowest screw speed had the most positive effect on the reduction of nanofiller agglomerates and exfoliation process. On the other hand, this process is hold only for successful intercalate agents. If the intercalation is not fruitful then different conditions could not affect the exfoliation process and could not lead to nanocomposite systems.

\section{ACKNOWLEDGMENTS}

This project was supported by the internal grant of TBU in Zlín No. IGA/16/FT/10/D funded from the resources of specific university research.

\section{REFERENCES}

1. R. A. Vaia, S. Vasudevan, W. Krawiec, L.G. Scanlon and E.P. Giannelis, Adv. Mater. 7, 154 (1995).

2. E. P. Giannelis, Adv. Mater. 8, 29-35 (1996).

3. Naoki Hasegawa, Hirotaka Okamoto, Makoto Kato, Arimistu Usuki, Norio Sato, Polymer 44(10), 2933-2937 (2003).

4. A. Kalendova, L. Kovarova, Z. Malac, J. Malac, J. Vaculik, J. Hrncirik, J. Simonik, Annual Technical Conference - Society of Plastics Engineers, Conference proceedings, 60th (Vol. 2), Dallas, USA, 2002, pp. 2250-2254.

5. A. Essawy Hisham, A. Abd El-Wahab Nourelhoda, A. Abd El-Ghaffar Mahmoud, Polymer Degradation and Stability 93(8), 1472-147 (2008).

6. N. Yarahmadi, I. Jakubowicz, T. Hjertberg, Polymer Degradation and Stability 95, 132-137 (2010).

7. L. I. Nass, Encyclopedia of PVC, Marvel Dekker Inc., USA, 1976. 
Copyright of AIP Conference Proceedings is the property of American Institute of Physics and its content may not be copied or emailed to multiple sites or posted to a listserv without the copyright holder's express written permission. However, users may print, download, or email articles for individual use. 